Mammals, however, are much less accessible to observation than birds and we have therefore happily been spared the emergence of any cult parallel to "birdwatching" and similar futilities. If the amateur naturalist wishes to study" mammals he must adopt at least some of the methods of the professional zoologist, much to the advantage of the subject and of himself. A large amount of interesting information has been recorded in the past few years through this quickening of interest, which has also shown what a vast field remains for exploration. The British Isles have a limited mammalian fauna, but any naturalist interested in it soon wants to know something of the much more numerous species of the continent. Dr. Corbet has written just the book to satisfy those seeking information about them.

The main part of the book is a systematic review of the mammals, except the cetaceans and the bats, of Europe west of Russia, in which the author gives a description of each species together with particulars of its distribution, and information on habitat, habits, reproduction and other items of its ecology and biology. The frequent recurrence of such phrases as "almost nothing has been recorded of the behaviour or ecology of this species" shows how much has yet to be learnt about many members of the fauna. Keys to identification are provided, as are distribution maps where necessary, and references are given to the more important literature.

Part 1 of the book, dealing with aspects of general mammalogy, is an excellent introduction to the study of mammals and discusses taxonomy, structure, distribution, life histories and ecology. The author admittedly deals more fully with matters in which he himself is interested, such as the important but neglected subject of scent and scent-glands, and successfully complements the text-book accounts of mammals with an individual approach.

The chapter on taxonomy is particularly valuable to the amateur naturalist who in the past has been sorely puzzled by what was more a competitive game than a branch of science. Dr. Corbet's very sound remarks, particularly about sub-species, clarify the subject admirably: the system of trinomials used early in this century "appeared to work well but in fact it owed its success in large measure to the incomplete geographical coverage of the available collections. It led in many cases to a greatly distorted and often quite erroneous picture of the variation present in nature. But as long as the limits of each taxon, including the species, were considered to be arbitrary and simply a matter of convenience the distortion was scarcely recognized". Up to the 'twenties and 'thirties of the present century nearly all the taxonomists working on mammals were ignorant of genetics and consequently produced a horrid muddle which their more enlightened successors are only now reducing to order.

The book is very well printed and produced, and is embellished with clear line drawings and a selection of good photographs. It will be a very welcome addition to the library of every British student of mammals.

L. Harrison Matthews

\section{QUANTUM BIOLOGY}

\section{Wave Mechanics and Molecular Biology}

Edited by Louis de Broglie. (Adiwes International Series in Biology.) Pp. v +186 . (Reading, Mass., and London: Addison-Wesley Publishing Company, 1966.) $66 s$.

THIs is an English translation of a volume first published some years ago in French. Although there is no preface, and no direct reference is made to the fact, the contents represent a series of lectures given by twelve authors, or groups of authors. As a result the individual chapters have no mutual cohesion, and are in the nature of summary reports of distinet topies.

Quantum biology is a relatively new field: and it is interesting to see the directions in which it is moving. It is still largely (but not wholly) concerned with $\pi$-electrons, and with charge transfer situations. It is still very limited in the "real" situations with which it deals, despite a claim made carly on that quantum biology is at last tackling real problems, because the effects are all studied in terms of a molecule, or group of molecules, in free space. Now there are practically no biological phenomena which occur in free space-they are usually in polar media, where ionicity, and hydration, will play a large part. So it is a pity that in this volume there is almost no reference at all to free energy, though there is a lot to say about ordinary energy.

But perhaps we should not be too critical. Any subject must start somewhere; and there is certainly some very suggestive material in these dozen reports. There is also enthusiasm. How right was Professor Bertrand to quote M. de Broglie: "Que c'est beau, l'enthousiasme". For there is certainly plenty of it in most of these accounts. With one or two exceptions, however, there is not much critical evaluation of the wave-mechanics used.

The topics eovered are those that might have been expected, such as carcinogenesis, energy bands in DNA, photosynthesis, chemotherapy. As studies in the state of the art in 1960 the chapters of this book form interesting and valuable reading. But it is difficult to see the point in republishing six years after the reviews were written. Most of the topics dealt with here have changed considerably in these six years, so that many of the reviews are seriously out of date. Books of this kind should be published within twelve months, otherwise it is better not to publish them at all.

C. A. Coulson

\section{TOAD STUDIES}

\section{Gnomes of the Night}

The Spadefoot Toads. By Arthur N. Bragg. Pp. 127. (Philadelphia: University of Pennsylvania Press; London: Oxford University Press, 1965.) 36s. net.

THIs small book deals with the habits of the burrowing spadefoot toads (Scaphiodus), a genus which is limited to North America. The author has pandered to the public only in the title of the book, apt though this is. Habits are described in relation to their adaptive significance in evolution. T'axonomy is mentioned only as a convenience on which to discuss differences of habit. The author, who is interested in amphibia generally, has made a special study of spadefoots for many years. But he is still finding new facts and, as he says, some toads have obviously not read his scientific papers. This is a scientific book and at the same time a very personal and readable book. It is more than a detailed account of a group of animals. In addition, it shows the author's reactions to his field observations. He details mistakes he has made and shows how his points of view and theories have changed as new facts have come to light.

Spadefoots depend for breeding places on temporary and shallow pools of water and have to be able to develop and metamorphose rapidly before their pool dries up. Bragg deals with the habits which assist them to do this. In social feeding large aggregations of tadpoles obtain more food from the bottom. Scooping aggregations deepen the pond locally and reduce the rate of evaporation. The author emphasizes in these two instances and in others that advantageous behaviour patterns are not always followed. The book has several pages of photographs, two distribution maps, an identification key and an extensive bibliography. 'The only thing it seems to lack is an account of how the spadefoot toad digs its burrow.
TOM WARWICK 